\title{
Cultural and Social Intelligences and Their Relationship to the Ability of Student Translators When Translating Cultural and Social Texts
}

\author{
Atefeh Saffarian (Corresponding author) \\ English Language Department, Imam Reza International University, Mashhad, Iran \\ Behzad Ghonsooly \\ English Language Department, Ferdowsi University, Mashhad, Iran \\ Omid Akbari \\ English Language Department, Imam Reza International University, Mashhad, Iran
}

Received: 08-11-2014

Accepted: 18-12- 2014

Published: 01-01- 2015

doi:10.7575/aiac.ijclts.v.3n.1p.45

URL: http://dx.doi.org/10.7575/aiac.ijclts.v.3n.1p.45

\begin{abstract}
The present study aims to investigate the relationship between cultural, social intelligences and student translators' ability in translating cultural and social texts. The predictive power of CQ subscales (cognitive, meta-cognitive, motivational, and behavioral) and SI subscales (social information processing, social skills, and social awareness) in the variance of translation scores were also examined. For the purpose of the study, a sample of 82 senior students of English Translation Studies comprised the participants of the study. Participants filled two questionnaires: the Cultural Intelligence Scale (CQS) and a Persian version of Tromso Social Intelligence Scale. They also received a rendering test of translation. The results of the analysis indicated that there is a significant relationship between cultural intelligence (CQ) and its subscales, social intelligence (SI) and its subscales and student translators' ability in translating cultural and social texts.
\end{abstract}

Keywords: Cultural Intelligence, Social Intelligence, Translation Ability, Translation of Cultural and Social Texts

\section{Introduction}

Comprehending why some people function more effectively than others in different cultural settings is increasingly essential while organizations globalize and the workforce becomes more diverse (Erez \& Earely, 1993; Gelfand, Erez, \&Aycan, 2007; Triandis, 1994). Furthermore, as the world is shrinking through globalization, the people come into contact with the people from different cultural backgrounds (Zakaria, 2000; Montagliani \& Giacalone, 1998). Accordingly, globalization increases not only cultural interactions but also possibility of cultural misapprehensions and conflict. Given the increase in globalization, individuals need to have skills to deal properly with people from various cultural situations.

According to Spearman (1904), research on human abilities is more than 100 years old. According to Thorndik (1920), only a few years after Spearman (1904) introduced academic intelligence, research on social intelligence started. The concept of social intelligence was originally described by Thorndike (1920) as "the ability to understand and manage men and woman, boys and girls - to act wisely in human relations" (p. 228). In fact, people are also required to have skills to comprehend and control individual feelings and emotions in order to manage interpersonal relationships in a global society.

It is obvious that so many factors such as strong memory and language competence involve in the task of translation which play major role in its success, yet translators' level of cultural and social intelligences can be influential factors in translation. Therefore, the purpose of this correlation study is to determine the relationship between cultural, social intelligences and student translators' ability in translating cultural and social texts. This study also seeks to examine which subscales of CQ and SI can best predict the ability of student translators in translating cultural and social texts.

\section{Literature Review}

This part presents a review of research on cultural intelligence, social intelligence, and translation ability. In fact, the purpose of this section is to provide a good theoretical basis for the research questions that this study explores.

\subsection{Cultural Intelligence}

According to Van Dyne, Ang, and Livermore (2010), the idea of cultural intelligence is derived from this question: why do some individuals but not others simply and effectively adjust their opinion and behaviors to culturally diverse situations? In order to respond to this question, Early and Ang (2003) made use of Stenberg and Detterman's (1986) four dimensions model of intelligence and based on it they developed a conceptual model of cultural intelligence (CQ). 
Therefore, understanding the issue of why some people are more successful than others in cross-cultural situations is the purpose of CQ research.

According to Earley and Ang (2003), CQ is comprised of metacognitive, cognitive, motivational, and behavioral dimensions. Metacognitive CQ refers to the mental processes that are used by individuals to acquire and comprehend cultural knowledge that leads to deep and better information processing, i.e. planning, monitoring, and revising mental models of cultural norms. Cognitive CQ refers to the knowledge of the norms and practices in various cultures acquired from personal experiences and education, i.e. knowledge of legal systems. Motivational CQ refers to the ability to direct attention and energy to learn about different cultures and function properly in cross-cultural situations. Finally, behavioral CQ refers to the ability to act verbally and non-verbally in a proper way when interacting with individuals from different cultures (Ang \& Van Dyne, 2008).

\subsection{Social Intelligence}

According to Dogan and Çetin (as cited in Ghadiri Moghaddam et al., 2013), for the first time when Thorndike in 1920 described intelligence as social, mechanical, and intellectual intelligence, social intelligence was studied seriously. Although since then many studies were conducted in the area of SI, these studies were always associated with problems because different scholars had different views on this area. In the study of social intelligence one of the main problems refers to the lack of agreement in definition of SI and the fact that researchers have defined SI in many ways (e.g., Barnes \& Sternberg, 1989; Ford \& Tisak, 1983, Keating, 1978). Some of these definitions focus on the capability to comprehend the other people or it can be said that they concentrate on cognitive components (e.g., Barnes \& Sternberg, 1989) and other scholars define SI as the capability to interact with others successfully and the focus is on behavioral aspects (Ford \& Tisak, 1983). Some of them concentrate on psychometric foundations and equated SI to the capability to act well in tests which measure social skills (Keating, 1978). The second problem refers to different aspects of social intelligence or the notion of multi-dimensionality of SI (Goleman, 2006). The third problem is whether social intelligence is distinct from general intelligence. Final problem of social intelligence is related to measure its structure. Various scales have been used to measure social intelligence. Primarily scales concentrated on the cognitive aspects of SI. Later scales were developed based on assessments and judgments of others, the interpretation of pictures and videos etc. (Dogan \& Cetin, 2009).

According to Silvera, Martinussen, and Dahl (2001), various types of social intelligence scales are not highly correlated with one another, mostly because of paucity of agreement in the definition of social intelligence and probability of bias in self-reports. Moreover, the implementations of some of these methods are time consuming and difficult. Consequently, in order to overcome these limitations, Silvera et al. (as cited in Ghadiri Moghaddam et al., 2013) developed a new self-report measure of SI. This scale measures three different areas of social intelligence: a) social information processing (SIP), b) social skills (SS), and c) social awareness (SA).

\subsection{Translation Ability (competence)}

According to Dimitrova and Jonasson (1999), translation ability is "a basic ability to understand, express, and reexpress the "same" or an "equivalent" meaning in more than one language, within the constraints given by the individual's competence in the respective languages" (p.1). According to Angelelli (ac cited in Ghonsooly, 2011), translation competence consists of three basic components: (1) understanding of the source language text (indicating a good comprehension of the source text by the rendered text); (2) translation techniques (conveying the full meaning of the original text and observing the target language flow and style which confirms translator's ability); and (3) writing in the target language (observing the criterion of coherence and proper grammar such as punctuation, spelling, syntax, usage and style).

Moreover, the most recent model of communicative translation competence is suggested by Angelelli (ac cited in Ghonsooly, 2011). Her model encompasses four sub-competences: (1) Linguistic Competence, (2) textual competence, (3) pragmatic competence, and (4) strategic competence. Besides, each of these competences is divided into subcomponents. Among these competences the sociolinguistic competence that is one of the sub-components of pragmatic competence takes several sub-competences which include the capability to choose words properly, knowledge of cultural references, knowledge of register, and knowledge of discourse.

As it was mentioned in Angelleli's communicative translation competence model, one of the sub-competences of sociolinguistic competence is knowledge of cultural references. Therefore, it can be pointed out that translators are required to comprehend the culture they are coping with to translate the text successfully.

In sum, due to the interdisciplinary nature of Translation Studies, translators and particularly translators or interpreters of cultural and social texts are confronted with texts from various cultures and societies. In order to deal with these texts properly, it is necessary for translators or interpreters to have the ability to adapt themselves to different cultures. In other words, it seems that translators need to be culturally and socially intelligent for a successful translation.

\subsection{Empirical studies on $C Q$ and $S I$}

To the best of the present researchers' knowledge, no similar research study has been carried out on the relationship between cultural, social intelligences and student translators' ability in translating cultural and social texts. However, it should be mentioned that in the field of management, psychology, and language teaching and learning there are more research materials that consider the cultural and social intelligences and their relationship with different variables in these fields. 
Some examples of these research studies are as follow: In 2012, RezaieeKelidbari, RezaieeDizgah, and RajabiJourshari conducted a study and examined the relationship between cultural intelligence and its dimensions with job performance. A sample of 217 operational staff in ports and maritime headquarters in Khuzestan Province comprised the participants of the study. So, collecting the data, analyzing them, and using Pearson's coefficient technique showed a positive relation existed between cultural intelligence, cognitive and motivation aspect and job performance. The results obtained from the Friedman test revealed that the motivational CQ and the cognitive CQ of staff have highest and lowest scores respectively. Moreover, in 2010, Vedadi, Kheiri, and Abbasalizadeh conducted a research study to explore the relationship between cultural intelligence and the achievement need of the managers. A sample of 78 middle and high managers of an Iranian company were selected. The results indicated a high correlation between cultural intelligence and its different dimensions including CQ of knowledge, strategy, motivation and behavior with the achievement need motif of the managers who had been studied. Indeed, the results of these studies are indicative of the existence of a significance relationship between cultural intelligence and different variables in various fields.

In addition, there are some studies that were conducted on the relationship between social intelligence with other variables. For example, in 2013, Shekarey, JannesariLadani, SedaghatRostami, and Jamshidi conducted a study to investigate the relationship between the social intelligence and aggression among the high school boy students in Kashan, Iran. Correlational method was used to examine the relationship between the social intelligence and aggression. Participants of the study included 3850 high school boy students of kashan. The results revealed that there was a significant relationship between the social intelligence and aggression; especially verbal aggression, physical aggression, violence, and hostility. Also, in 2008, Dong, Koper, and Collaço conducted a study to explore the relationship between social intelligence and intercultural communication sensitivity. The relationship between selfesteem and intercultural communication sensitivity was examined too. A sample of 419 undergraduates at two universities in the western United States comprised the participants of the study. Results indicated a significant relationship between social intelligence (SI) and intercultural communication sensitivity (ICS). Besides, both dimensions of self-esteem - self-worth and self- efficacy - were significantly related to ICS. The results of these studies revealed that SI and the other variables under the research are positively correlated.

\section{Research Questions}

Since there are limited empirical findings concerning cultural, social intelligences and translation ability, the present researchers have tried to provide answer to the following questions:

1. Is there any significant relationship between cultural intelligence and student translators' ability in translating cultural and social texts?

1.1. Is there any significant relationship between subscales of CQ including metacognitive, cognitive, motivational, and behavioral CQ and student translators' ability in translating cultural and social texts?

2. Is there any significant relationship between social intelligence and student translators' ability in translating cultural and social texts?

2.1. Is there any significant relationship between subscales of SI including social information processing, social skills, and social awareness and student translators' ability in translating cultural and social texts?

3. Which subscales of CQ can best predict the ability of student translators in translating cultural and social texts?

4. Which subscales of SI can best predict the ability of student translators in translating cultural and social texts?

\section{Method}

\subsection{Participants}

The participants who took part in this study were senior students of English translation at BA level. However, because of lack of cooperation of some participants who did not fully cooperate and answer all the questions, the number of the participants decreased from 93 to 82. So, the final number of participants in this study consisted of 82 Iranian senior translation students of Tabaran and Imam Reza Universities of Mashhad. The age of the participants ranged between 20-25 years old. Both male and female learners participated in this study. There were some reasons for choosing participants from senior students. First, it was considered that these students had adequate translation knowledge because of their academic instructions. Second, due to passing the related translation courses, these students had some experience in translation practice. In fact, the sample of this study passed different courses in advance. They passed some courses for improving their general knowledge of English e.g. Reading, Writing, and Speaking courses. In addition, they passed some advanced courses of translation e.g. General Linguistics, Theoretical Foundation and Principles of Translation, and practical courses of translation such as translating different texts from simple to advanced English texts.

\subsection{Procedure}

In order to fulfill the purpose of this study through research process and collecting data, the cultural intelligence and social intelligence questionnaires were administered to 82 senior translation students. Data collection took place within the first two weeks of the 2014 winter semester. Actually, it took two sessions for each group of students. In the first session all subjects were asked to fill in the cultural intelligence questionnaire (CQS) in order to determine their level of cultural intelligence. Another questionnaire was the Persian version of Social Intelligence Scale developed by Silvera et al. (2001). It was disseminated among participants in order to determine their level of social intelligence. The 
participants were given 20 minutes to answer the questions of both questionnaires. Both of the Social and Cultural questionnaires were applied in a pen and paper format. Both questionnaires were scored by the present researchers based on their guidelines.

In the second session, the participants were asked to translate a cultural and social English text to Persian as a rendering test. This text was about White Nights festival in St. Petersburg, Russia. It consisted of two paragraphs and was fairly difficult to read. The time for translation was 1 hour and using dictionary was optional. The rendering text based on Waddington's model of translation assessment (2001) was scored by one of the researchers and two other raters.

According to Waddington (2001), method A that was used in this study for assessing the students' quality of translation is the work of Hurtado Albir (as cited in Waddington, 2001) who developed a list of possible errors based on three categories:

1) Inappropriate renderings which affect the understanding of the source text

2) Inappropriate renderings which affect expression in the target language

3) Inadequate renderings which affect the transmission of either the main function or secondary functions of the source text.

\subsection{Instruments}

\subsubsection{Cultural Intelligence Scale}

The cultural intelligence scale which was used in this study was developed and validated by Ang et al. (2007). This questionnaire is composed of 20 items which measure the main aspects of cultural intelligence using a seven-point Likert scale for each item (ranging from $1=$ strongly disagree to $7=$ strongly agree). There are 4 items for metacognitive $\mathrm{CQ}($ alpha $=.76), 6$ items for cognitive CQ (alpha $=.84), 5$ for motivational CQ (alpha $=.76)$, and 5 for behavioral CQ $($ alpha $=.83)$.

\subsubsection{Tromso Social Intelligence Scale}

The Persian version of Social Intelligence Scale developed by Silvera et al. (2001) was used to reveal social intelligence level of participants. It should be noted that the validity and reliability of the scale was calculated by Rezaiee (2010). This scale consists of 21 items and each item is evaluated on a 7-point scale. The TSIS measures social intelligence on the basis of social information processing, social skills, and social awareness.

In Rezaiee's study (2010), after confirming validity, the reliability of the scale was computed using Cronbach's alpha. Cronbach alpha internal consistency coefficients for three subscales were reported as follow: social information processing (alpha $=73)$, social skills (alpha $=.66$ ), and social awareness (alpha $=.64)$; and the total was .75 . In addition, the test-retest reliability for social information processing, social skills, and social awareness were reported $.76, .86$ and .66 respectively. The test-retest reliability for total scale was .81. So, the results show that the reliability of each factor is in acceptable level.

\subsubsection{Rendering and Transferring Test}

A cultural and social English text of 234 words was given to the participants to be translated into Persian. This text was taken from a valid web site by Chip Conley (2014). This web site presents a list of the world's best festivals with good information about each of them. Since the focus of this study was on a cultural and social text as a rendering test the researchers preferred to choose a text that was about a festival in Russia. In fact, in researchers' point of view the text was appropriate for the purpose of this study because it was full of cultural words and provided sound information about the culture of a particular society. In addition, the readability of the text was calculated to show how easy or difficult this text is. So, the text had the readability of 54.1 which confirmed the suitability of that for senior students.

\subsection{Research Design}

This study used multivariate correlational research design to answer the research questions. When a researcher desires to investigate the relationships between variables, correlational research designs are used.

\subsection{Data Analysis}

In order to answer the first research question, the Pearson Correlation Coefficient was used between the cultural intelligence and translation scores via the latest version of Statistical Package which is used for Social Science (SPSS). To answer the second research question, the Pearson Correlation Coefficient was used. In addition, the correlation between translation ability and subscales of $\mathrm{CQ}$ (metacognitive $\mathrm{CQ}$, cognitive $\mathrm{CQ}$, motivational $\mathrm{CQ}$, and behavioral CQ) and SI (SIP, SS and SA) was separately computed by the researchers. Standard regression was also conducted to see whether CQ subscales and SI subscales are predictors of translation ability or not.

\section{Results}

Table 1 gives the descriptive statistics of the instruments used, that is CQ and its components, SI and its components, and translation tests. The number of participant, mean, and standard deviation of the data can be seen in this table. 
Table 1. Descriptive Statistics of the Instruments

\begin{tabular}{lcccccccccc}
\hline & \multicolumn{7}{c}{ Descriptive Statistics } & & & \\
& $\begin{array}{c}\text { Cog } \\
\text { CQ }\end{array}$ & $\begin{array}{c}\text { Beh } \\
\text { CQ }\end{array}$ & $\begin{array}{c}\text { Met } \\
\text { CQ }\end{array}$ & $\begin{array}{c}\text { Mot } \\
\text { CQ }\end{array}$ & CQ & SIP & SS & SA & SI & Trsc \\
\hline \multicolumn{1}{c}{ N Valid } & 82 & 82 & 82 & 82 & 82 & 82 & 82 & 82 & 82 & 82 \\
\hline Missing & 0 & 0 & 0 & 0 & 0 & 0 & 0 & 0 & 0 & 0 \\
& & & & & & & & & & \\
\hline Mean & 22.51 & 21.50 & 18.34 & 23.50 & 85.85 & 43.22 & 27.93 & 28.17 & 99.32 & 16.35 \\
\hline Std. & 6.73 & 5.79 & 4.11 & 6.43 & 18.05 & 7.09 & 8.30 & 6.64 & 20.03 & 1.83 \\
Deviation & & & & & & & & & & \\
\hline Minimum & 6.00 & 5.00 & 5.00 & 7.00 & 38.00 & 23.00 & 11.00 & 7.00 & 42.00 & 10.00 \\
\hline Maximum & 39.00 & 33.00 & 27.00 & 35.00 & 115.00 & 55.00 & 45.00 & 43.00 & 140.00 & 19.50 \\
\hline
\end{tabular}

Note 1: metCQ stands for meta-cognitive $\mathrm{CQ}, \operatorname{cog} C Q$ for cognitive CQ, motCQ for motivational CQ, behCQ for behavioral CQ, SIP for social information processing, SS for social skills, SA for social awareness, and Trsc for translation score.

According to Table 1, the mean and standard deviation for total CQ were $M=85.85$ and $S D=18.05$. The mean and standard deviation for total SI were $M=99.32$ and $S D=20.03$. In addition, the mean and standard deviation for translation scores were $M=16.35$ and $S D=1.83$.

The pilot study of translation scores clarified that there was a significant correlation among the three raters the details of which are presented in Table 2.

Table 2. Inter-Rater Reliability of Translation Scores

\begin{tabular}{ccccc}
\hline & & Rater 1 & Rater 2 & Rater 3 \\
\hline Rater 1 & Pearson Correlation & 1 & $.913^{* *}$ & $.908^{* *}$ \\
& Sig. (2-tailed) & & .000 & .000 \\
& $\mathrm{~N}$ & 82 & 82 & 82 \\
\hline Rater 2 & Pearson Correlation & $.913^{* *}$ & 1 & $.904^{* *}$ \\
& Sig. (2-tailed) & .000 & & .000 \\
& N & 82 & 82 & 82 \\
\hline Rater 3 & Pearson Correlation & $.908^{* *}$ & $.904^{* *}$ & 1 \\
& Sig. (2-tailed) & .000 & .000 & \\
& N & 82 & 82 & 82 \\
\hline
\end{tabular}

**. Correlation is significant at the 0.01 level (2-tailed).

As it is depicted in Table 2, the correlation coefficient between the scores of Rater 1 and 2 was .91, Rater 1 and 3 was .90 , and finally Rater 2 and 3 was .90 which were all significant at 0.01 level in a two-tailed test.

This study tries to investigate the relationship between cultural, social intelligences and translation ability. The Pearson product moment correlation formula was used because the data obtained are interval. The relationships between variables are presented in Table 3.

Table 3. Pearson Correlation Coefficient Test Results

\begin{tabular}{lcll}
\hline & Correlation & Sig & Result \\
\hline CQ & $.780^{* *}$ & .000 & Confirmed \\
MetCQ & $.390^{* *}$ & .000 & Confirmed \\
CogCQ & $.964^{* *}$ & .000 & Confirmed \\
Mot CQ & $.509^{* *}$ & .000 & Confirmed \\
BehCQ & $.468^{* *}$ & .000 & Confirmed \\
SI & $.793^{* *}$ & .000 & Confirmed \\
SIP & $.590^{* *}$ & .000 & Confirmed \\
SS & $.771^{* *}$ & .000 & Confirmed \\
SA & $.797^{* *}$ & .000 & Confirmed \\
\hline
\end{tabular}


As can be seen in Table 3, the Pearson correlation coefficient between cultural intelligence and translation scores was $(\mathrm{r}=.78, \mathrm{p}<.01)$. So, there is a significant positive relationship between CQ and translation ability. Moreover, according to Table 3, all subscales of CQ (e.g. metacognitive CQ, cognitive CQ, motivational CQ and behavioral CQ) were positively correlated with translation ability.

Additionally, according to Table 3, the Pearson correlation coefficient between social intelligence and translation scores was $(\mathrm{r}=.79, \mathrm{p}<.01)$. So, there is a significant positive relationship between SI and translation ability. Besides, according to Table 3, all subscales of SI (e.g. social information processing, social skills, social awareness) were positively correlated with translation ability.

To determine how much overall variance is explained by the predictor variables (metacognitive CQ, cognitive CQ, motivational CQ, and behavioral $\mathrm{CQ}$ ), the researchers conducted a standard multiple regression.

The question that is dealt with in this part is whether CQ subscales can predict translation ability.

Table 4. Regression Coefficient CQ Components and Translation Scores

\begin{tabular}{ccccc}
\hline $\mathrm{R}$ & $\mathrm{R}$ Square & $\begin{array}{c}\text { Adjusted R } \\
\text { Square }\end{array}$ & $\begin{array}{c}\text { Std. Error of } \\
\text { the Estimate }\end{array}$ & $\begin{array}{c}\text { Durbin- } \\
\text { Watson }\end{array}$ \\
\hline $.969^{\mathrm{a}}$ & .938 & .935 & .46557 & 1.504 \\
\hline
\end{tabular}

a. Predictors: (Constant), Cog, Mc, Mot, Beh

b. Dependent Variable: Tr. Scores

As can be seen in Table 4, R equals .96. R square equals .93. Since $r$ square can be interpreted in terms of percentage of predicted variation; so, it can be said that scores on CQ components can predict 93 percent of the variance in translation ability.

The analysis of variance (ANOVA) shows whether the regression equation is significant.

Table 5. Regression Meaningfulness Table on CQ Components and Translation Scores

\begin{tabular}{ccccccc}
\hline & Model & Sum of Squares & Df & Mean Square & F & Sig. \\
\hline 1 & Regression & 254.667 & 4 & 63.667 & 293.725 & $.000^{\mathrm{a}}$ \\
& Residual & 16.690 & 77 & .217 & & \\
& Total & 271.357 & 81 & & & \\
& & & & & \\
\hline
\end{tabular}

a. Predictors: (Constant), Cog, Mc, Mot, Beh

b. Dependent Variable: Tr. Scores

The result obtained from Table 5 shows that the amount of $F$ is meaningful $(F=293.72, p<.05)$. So, it can be said that the translation ability can be predicted by CQ components.

In linear regression, the size of the coefficient for each independent variable shows the size of the effect that the variable has on the dependent variable.

Table 6. Coefficients of Standardized Effects of Regression CQ Components and Translation Scores

\begin{tabular}{cccccccc}
\hline \multirow{2}{*}{ Model } & \multicolumn{2}{c}{$\begin{array}{c}\text { Unstandardized } \\
\text { Coefficients }\end{array}$} & $\begin{array}{c}\text { Standardized } \\
\text { Coefficients }\end{array}$ & & & $\begin{array}{c}\text { Collinearity } \\
\text { Statistics }\end{array}$ \\
\cline { 2 - 4 } & B & Std. Error & Beta & $T$ & Sig. & Tolerance \\
\hline (Constant) & 9.767 & .266 & & 36.721 & .000 & \\
Behavioral CQ & .010 & .012 & .030 & .803 & .002 & .559 \\
Metacognitive CQ & .034 & .015 & .077 & 2.229 & .029 & .667 \\
Motivational CQ & .05 & .011 & .019 & .480 & .001 & .518 \\
Cognitive CQ & .250 & .009 & .918 & 28.131 & .000 & .750 \\
\hline
\end{tabular}

a. Dependent Variable: Tr. Scores

According to Table 6, the amount of $b$ values for CQ components was .25 for Cognitive CQ, .05 for Motivational CQ, .03 for Metacognitive CQ, and .01 for Behavioral CQ. So, cognitive CQ can best predict the translation ability of students. 
Furthermore, to determine how much overall variance is explained by SI components (SIP, SS, and SA), the researchers conducted a standard multiple regression.

This part indicates the predictive power of SI subscales in relation to translation ability.

Table 7. Regression Coefficient SI Components and Translation Scores

\begin{tabular}{ccccc}
\hline $\mathrm{R}$ & R Square & $\begin{array}{c}\text { Adjusted R } \\
\text { Square }\end{array}$ & $\begin{array}{c}\text { Std. Error of } \\
\text { the Estimate }\end{array}$ & $\begin{array}{c}\text { Durbin- } \\
\text { Watson }\end{array}$ \\
\hline $.806^{\mathrm{a}}$ & .649 & .635 & 1.10516 & 1.889 \\
\hline
\end{tabular}

a. Predictors: (Constant), SIP, SA, SS

b. Dependent Variable: Tr. Scores

According to Table 7, $\mathrm{R}$ equals .80. R square equals .64. Since $\mathrm{r}$ square can be interpreted in terms of percentage of predicted variation; so, it can be said that scores on SI components can predict 64 percent of the variance in translation ability.

Table 8. Regression Meaningfulness Table on SI Components and Translation Scores

\begin{tabular}{ccccccc}
\hline & Model & Sum of Squares & Df & Mean Square & F & Sig. \\
\hline 1 & Regression & 176.089 & 3 & 58.696 & 48.057 & $.000^{\mathrm{a}}$ \\
& Residual & 95.268 & 78 & 1.221 & & \\
Total & 271.357 & 81 & & & \\
\hline
\end{tabular}

a. Predictors: (Constant), SS, SIP, SA

b. Dependent Variable: Tr. Scores

The result obtained from Table 8 shows that the amount of $F$ is meaningful $(F=48.05, p<.05)$. So, it can be said that the translation ability can be predicted by SI components.

Table 9. Coefficients of Standardized Effects of Regression SI Components and Translation Scores

\begin{tabular}{cccccccc}
\hline \multirow{2}{*}{ Model } & \multicolumn{2}{c}{$\begin{array}{c}\text { Unstandardized } \\
\text { Coefficients }\end{array}$} & $\begin{array}{c}\text { Standardized } \\
\text { Coefficients }\end{array}$ & & & \multicolumn{2}{c}{$\begin{array}{c}\text { Collinearity } \\
\text { Statistics }\end{array}$} \\
\cline { 3 - 5 } & & $\mathrm{B}$ & Std. Error & Beta & $\mathrm{T}$ & Sig. & Tolerance \\
\hline 1 & (Constant) & 9.133 & .857 & & 10.659 & .000 & \\
& SA & .218 & .022 & .144 & 1.662 & .002 & .928 \\
& SS & .019 & .084 & .792 & 2.591 & .032 & .736 \\
& SIP & .037 & .066 & 087 & .291 & .046 & .782 \\
\hline
\end{tabular}

a. Dependent Variable: Tr. Scores

According to Table 9, the amount of $b$ values for SI components was .03 for social information processing, .01 for social skills, and .21 for social awareness. Therefore, social awareness can best predict the translation ability of students.

\section{Discussion}

The purpose of this study was to investigate the relationship between cultural, social intelligences and student translators' ability in translating cultural and social texts. Furthermore, this study seeks to examine which subscales of CQ and SI can best predict the ability of student translators in translating cultural and social texts.

In the present study the concept of cultural intelligence is regarded as a particular form of intelligence focused on the individual's capability to adapt and communicate appropriately with different cultural contexts. Also, social intelligence is considered as the capability of the individual in comprehending and managing others and engaging in adaptive social interactions.

The correlational findings indicated that there is a significant relationship between cultural intelligence and student translators' ability in translating cultural and social texts. Since no studies have explored the relationship between cultural intelligence and student translators' ability in translating cultural and social texts in the field of translation studies, the result of the present study seems to be beneficial in this field. In fact, such a study provides sound 
information to be taken into consideration by policy makers, language planner, curriculum designers, text books developer, language instructors, teachers as well as learners. It provides them with opportunities to look differently at the curriculum, instruction, and assessment based on cultural intelligence. Therefore, because of the important role of CQ in relation to translation ability that was revealed by the result of this study, CQ should be considered in pedagogical policies in translation studies. In addition, CQ test can be used by different organizations as qualification criteria for selecting translators. As it was stated by Livermore (2011) CQ is improvable and teachers can develop programs to improve cultural intelligence of their students to have better translation performance.

Moreover, the relationship between each subscale of cultural intelligence (metacognitive CQ, cognitive CQ, behavioral $\mathrm{CQ}$, and motivational $\mathrm{CQ}$ ) and translation ability of students in translating cultural and social texts was examined separately in this study. The results show that there is a significant relationship between each individual subscale of CQ and translation ability. Although all subscales of CQ are highly correlated with translation ability, among them cognitive CQ, which is the individual knowledge of the rules, customs, and behaviors of the other culture, is the best predictor of translation ability. In fact, this finding is consistent with Ghonsooly and Shalchy (2013), who found that cognitive CQ is the best predictor of writing and fluency. In addition, in 2013, Ghasemipour conducted a study to investigate the relationship between cultural intelligence, ambiguity tolerance and translation ability of Iranian English translation students. The results of this study showed that there was a significant positive relationship between cultural intelligence, ambiguity tolerance and translation ability of students. Also, this study revealed that cultural intelligence can best predict translation ability of students. Moreover, in 2014, Ashiani conducted a study and examined the relationship between social, cultural intelligences and literary translation ability of students of translation studies. The findings of this study proved that there was significant relationship between social, cultural intelligences and the ability of the literary translation. Although both of the intelligences can predict the literary translation ability of the sample, CQ had more predictive power than SI. Besides, this study showed that motivational CQ had more predictive power than the other subscales. Therefore, the results of the present study are consistent with the result of the previous studies.

Based on Angelelli's model of communicative translation competence the reasons of why cognitive CQ is the best predictor can be discussed. Indeed, the most recent model of communicative translation competence is proposed by Angelelli (as cited in Ghonsooly, 2011) and this model comprises four sub-competences: (1) linguistic competence, (2) textual competence, (3) pragmatic competence, and (4) strategic competence. Sociolinguistic competence is the subcompetences of pragmatic competence. Having knowledge of cultural references is one of the factors that were taken into consideration by Angelelli as a sub-category of sociolinguistic competence. So, based on the Angelelli's model of communicative translation competence, translators should have knowledge about the culture of both ST and TT. In other words, the knowledge of cultural norms is required for translators in order to produce better translation.

In addition, cognitive ability is one of the sub-categories of strategic competence. According to Ghonsooly and Shalchy (2013), the cognitive demands of working memory can be decreased by having high cultural knowledge about the addressee from various cultures. Thus, translators who have high level of cognitive CQ can better find a solution for their translation problems. Moreover, if their cognitive CQ improves, they need less cognitive efforts in order to find proper strategies for translating the text and they are more successful in the process of translation.

Furthermore, the results of this study revealed that there is a significant relationship between social intelligence and translation ability of students in translating cultural and social texts. . In other words, social intelligence is highly correlated with translation ability. Indeed, this result is consistent with Al-Makahleh and Ziadat (2012), who found that SI and the behavioral characteristics of talented secondary school students are positively correlated. In addition, all subscales of social intelligence (social information processing, social skills, and social awareness) are significantly correlated with translation ability of students in translating cultural and social texts. There are some studies that were conducted on the relationship between SI with other variables that are consistent with the result of this study. For example, in 2013, Ghadiri Moghaddam et al. conducted a study to investigate the effects of social intelligence of managers and performance of brokerage firms in Tehran Stock Exchange. The results indicated that social intelligence of managers has a positive and significant impact on the performance of the brokerage firms in Tehran Stock Exchange. Furthermore, SI subscales (social information processing of managers, social skills, and social awareness) had a significant effect on the performance of brokerage firms. In this study social skills of managers had most effect and social information processing of managers had least effect. In addition, as it was mentioned earlier, in 2014, Ashiani conducted a study to investigate the relationship between social, cultural intelligences and literary translation ability of students. The findings of this study showed that there is a significant relationship between literary translation ability of students and their social intelligence. Moreover, among the three subscales of SI (SIP, SS, and SA) which were positively correlated with translation ability, social skills had more predictive power than the others.

As it was mentioned above, there is a significant relationship between each subscale of SI (SIP, SS, and SA) and translation ability but among these subscales social awareness (SA) is the best predictor of translation ability. Social Awareness measures the ability of active behaving in accordance with the situation, place, and time. In fact, having a high level of social awareness, translators are more conscious of their performance in the process of translation. In addition, they are aware of the context of the text and based on it they translate the text actively. In conclusion, based on the definition of social awareness and type of the text used in this study, it seems that the participants that have a high level of social awareness are more familiar with St. Petersburg, Russia as a social context of the rendering text. Accordingly, this familiarity affects their translation performance, causing to translate the text actively, and increasing the quality of translation product. According to Gill and Guzman (2011), in the globalized word, considering social 
awareness and teaching of it in translation programmes has become a humanitarian necessity. They believed that it is the responsibility of the teacher to empower students through helping them develop their critical awareness, their own social vision that can help them engage in the ever-changing societies (Gill \& Guzman, 2011). Generally speaking, it is essential for translators to maintain a high level of social awareness in the globalized word.

To sum up, according to the results of the study, both CQ and SI play a significant role on the process of translation and individuals with high level of cultural and social intelligences are more successful translators. To analyze the reasons of these obtained results, it should be stated that the participants who are culturally and socially intelligent are more familiar with the cultural and social context of the text; what is more, they are more aware of complexities of differences between cultures. Therefore, in the process of translation when they encounter these complexities they use the best strategies to cope with them. However, analyzing the data revealed that there are a few participants with a low level of cultural or social intelligences that translate the text properly. The causes of this finding could be discussed based on Angelelli's model of communicative translation competence. In fact, one of the sub-competences of her model is linguistic competence. Angeleli considers knowledge of grammar, spelling, and punctuation as relevant abilities which constitute linguistic competence. Consequently, it seems that the linguistic competence of these small samples had an effect on their quality of translation product. It is noteworthy that cultural and social intelligence are not just the factors which influence the translation ability and the other factors such as linguistic competence have to be taken into consideration.

\section{Conclusion}

This study and its results have several remarkable implications for teachers, instructors, and other researchers. The results of the present study indicate a positive relationship between cultural, social intelligences and student translators' ability in translating cultural and social texts. Accordingly, the results of this study can highlight the importance of these intelligences in the process of translation and inform teachers and instructors. Those who teach translation and administration of translator training institution or universities can benefit from considering the concepts of cultural and social intelligences to make systematic programs for instruction and learning. Actually, this study can be useful for them to provide their educational curriculum and design their syllabus based on these intelligences in order to make students familiar with these concepts and use proper strategies for improving their CQ and SI.

Furthermore, the increasing tendency toward the globalization provide the opportunity for translation experts to have multilingual job in different fields, so the demand for hiring professionals and well-experienced translators and interpreters with high level of cultural and social intelligences among public and private entities has substantially increased. Hence, these organizations can administer CQ and SI scales as qualification criteria during the hiring process for selecting translators appropriately.

\section{References}

Al-Makahleh, A., \& Ziadat, A. H. (2012). Social intelligence and personal characteristics of talented secondary school students in King Abdullah II schools for excellence, Jordan. Educational Research, 3(10), 785-798.

Ang, S., \& Van Dyne, L. (2008). Conceptualization of cultural intelligence: Definition, distinctiveness, and nomological network. In S. Ang \& L. Van Dyne (Eds.), Handbook of cultural intelligence: Theory, measurement, and applications (pp.3-15). New York, NY: Sharpe.

Ang, S., Van Dyne, L., Koh, C., Ng, K. Y., Templer, K. J., Tay, C., \&Chandrasekar N. A. (2007). Cultural Intelligence: its measurement and effects on cultural judgment and decision making, cultural adaptation and task performance. Management and Organization Review, 3(3), 335- 371. http://dx.doi.org/ 10.1111/j.1740-8784.2007.00082.x

Barnes, M. L., \& Sternberg, R. J. (1989). Social intelligence and decoding of nonverbal cues. Intelligence, 13(3), 263287. http://dx.doi.org/10.1016/0160-2896(89)90022-6

Conley, C. (2014). Stars of the White Nights. [Online] Available: http://www.fest300.com/festivals/stars-of-the-whitenights (November 18, 2013)

Dogan, T., \& Çetin, B. (2009). Validity, reliability and factorial structure of the Turkish version of the Tromsø Social Intelligence Scale. Educational Sciences: Theory \& Practice, 9(2), 709-720.

Dong, Q., Koper, R. J., \& Collaco, C. M. (2008).Social intelligence, Self- esteem, and Intercultural communication sensitivity. Intercultural Communication Studies, 17(2), 162-172.

Earley, P. C., \& Ang, S. (2003). Cultural intelligence: Individual interactions across cultures. Palo Alto, CA: Stanford University Press.

Erez, M., Earley, P. C. (1993). culture, self-identity, and work. New York: Oxford University Press.

Ford, M. E., \& Tisak, M. S. (1983). A further search for social intelligence. Journal of Educational Psychology, 75(2), 196-206. http://dx.doi.org/10.1037/0022-0663.75.2.196

Gelfand, M. J., Erez, M., \&Aycan, Z. (2007).Cross-cultural organizational behavior. In S.T.Fisk, D. L. Schacter, \& C. Zahn-Waxler (Eds.), Annual Review of Psychology (Vol.58, pp. 479- 514). Palo Alto, CA: Annual Reviews. 
GhadiriMoghaddam, A., Sami Kermani, S., Ghorbani, M., \&Sadeghi, F. S., \&Sardarabadi, P. (2013). The relationship between social intelligence of managers and performance of brokerage firms: Evidence from Tehran stock exchange. Interdisciplinary journal of contemporary research in business, 5(3), 681- 687.

Ghonsooly, B. \& Shalchy, S. (2013).Cultural intelligence and writing ability: Delving intofluency, accuracy and complexity. Novitas-ROYAL (Research on Youth and Language), 7(2), 147-159.

Gill, R. M., \& Guzmán, M. C.(2011).Teaching Translation for Social Awareness in Toronto.The Interpreter and

Translator Trainer, 5(1), 93-108. http://dx.doi.org/10.1080/13556509.2011.10798813

Goleman, D. (2006). Social intelligence: The new science of human relationships. New York: Bantam Books.

Keating, D. P. (1978). A search for social intelligence. Journal of Educational Psychology, 70(2), 218- 223.

Livermore, D. (2011). The cultural intelligence difference: Master the one skill you can't do without in today's global economy. New York, NY: AMACOM.

Montagliani, A., \& Giacalone, R. A. (1998). Impression management and cross-cultural adaption. The Journal of Social Psychology, 138(5), 598-608. http://dx.doi.org/10.1080/00224549809600415

Rezaiee, A. (2010). Validity, Reliability and Factorial Structure of the Persian Version of the Tromsø Social

Intelligence Scale. Journal of Scientific Research of University of Tabriz, 20, 70-87.

RezaieeKelidbari, H. R., RezaieeDizgah, M., \&RajabiJourshari, P. (2012). The relationship between Cultural Intelligence and Job Performance of operational staff in ports (Case Study: Ports and Maritime

Headquarters inKhuzestan Province-Iran). Journal of Basic and Applied Scientific Research, 2(6), 6133-6138. Retrieved from

http://www.textroad.com/pdf/JBASR/J.\%20Basic.\%20Appl.\%20Sci.\%20Res.,\%202(6)6133-6138, \%202012.pdf

Shekarey, A., JannesariLadani, H., SedaghatRostami, M., \&Jamshidi, M. (2013). On the Relationship between the Social Intelligence and Aggresion: A Case Study of High School Boy Students. International Journal of Education, 5(1), 94-102. http://dx.doi.org/10.5296/ije.v5i1.2378

Silvera, D. H., Martinussen, M., \& Dahl T. I. (2001). The Tromso Intelligence Scale aa self-report measure of social intelligence. Scandinavian Journal of Psychology, 42(4), 313-319. http://dx.doi.org/10.1111/1467- 9450.00242

Spearman, C. (1904). "General intelligence" objectively determined and measured. American Journal of Psychology, 15, 201-293.

Sternberg, R. J., Detterman, D.K. (1986).What is intelligence? Contemporary viewpoints on its nature and definition. Norwood, NJ: Ablex.

Thorndike, E. L. (1920). Intelligence and its use. Harper's Magazine, 140, 227-235. Retrieved From https://docs.google.com/viewer?url=http://64.62.200.70/PERIODICAL/PDF/Harpers-1920jan/8594/\&chrome=true

Triandis, H. C. (1994). Culture and Social Behavior. New York: McGraw-Hill.

Van Dyne, L., Ang, S., \& Livermore, D. (2010).Cultural intelligence: A pathway for leading in a rapidly globalization world. In k. M. Hannum, B. MCFeeters, \& L. Booysen (Eds.), Leading across differences: Cases and perspectives. San Francisco, CA: Pfeiffer.48.

Vedadi, A., Kheiri B., \&Abbasalizadeh, M. (2010). The relationship between cultural intelligence and achievement: a case study in an Iranian company. Iranian Journal of Management Studies, 3(3), 25-40.

Waddington, C. (2001). Different methods of evaluating student translations: The questions of validity. Meta: Translators' Journal, 46(2), 311-325. http://dx.doi.org/10.7202/004583ar

Zakaria, N. (2000). The effects of cross-cultural training on the acculturation process of the global workforce. International Journal of Manpower, 21(6), 492-510. http://dx.doi.org/10.1108/01437720010377837 